\title{
Effects of a Data Driven, Individualized and Multifaceted Intervention Program on Eighth Grade Students' Achievement in Mathematics
}

\author{
Rusen Meylani (Corresponding author) \\ Mary Lou Fulton Teachers College, Arizona State University \\ 1151 S. Forest Ave., Tempe, Arizona 85281, United States
}

Tel: 1-480-249-4218Ｅ-mail: rmeylani@asu.edu

Received: August 10, 2014 Accepted: September 30, 2014 Published: October 17, 2014

doi:10.5296/ire.v3i1.6119 URL: http://dx.doi.org/10.5296/ire.v3i1.6119

\begin{abstract}
This paper reveals the results of a data driven, individualized and multifaceted intervention program piloted at a southwestern urban school district at a Title I minority school that served free breakfast and lunch to $99 \%$ of the students. Results of the benchmark tests as well as the statewide high-stakes tests show that the intervention was a success. The success of the intervention program was due to not only its careful planning but also the careful execution of its aspects that were all in place. The intervention proved to be a cheap, scalable strategy that can be implemented to improve the performance of high-poverty schools. As a result, the intervention program became the district-wide standard practice in the new school year.
\end{abstract}

Keywords: Data driven, individualized and multifaceted intervention, Galileo benchmark test, state-wide high stakes test, AIMS, professional development, Title I minority school

\section{Introduction}

While the U.S.'s ability to compete in the global economy is decreasing and the need for more experts in STEM fields is increasing (Couto, 2007; NRC, 2007; U.S. Department of Labor, 2007; U.S. Congress Joint Economic Committee 2012), the number of students pursuing and completing STEM degrees is declining (National Science Board, 2010). The prevailing view of the STEM career progression is that as young children move through the educational system, interest is lost at every stage (Riegle-Crumb, Moore, \& Ramos-Wada, 2011). As longitudinal studies confirm, this decline in the interest for STEM related careers following middle school, is due to students' poor preparation for, lack of success with, and 
little interest in mathematics (Arizona Department of Education, 2009; Mullis, Martin, \& Foy, 2008; Ischinger, 2007; Kier, 2013).

Data from a number of international, national and state assessments attest to students' poor understanding or lack of recall of important mathematical concepts and skills. The international comparisons as well as performance on domestic examinations suggest that problems in U.S. STEM education may begin as early as elementary school and continue through students' secondary and post-secondary education (Riegle-Crumb, Moore, \& Ramos-Wada, 2011). On the most recent Programme for International Student Assessment (PISA) of 15-year-olds, administered in 2012, U.S. students' average score was 481, that is, 13 points less than the international average of 494 with U.S. 15-year-olds ranked 25th in math in PISA scores among OECD nations (Kelly et al., 2013). On the mathematics portion of the 2011 Trends in International Mathematics and Science Study (TIMSS), the average score for grade 4 U.S. students was 541. By grade 8, the average score decreased to 509 (Institute of Education Sciences, 2011). The most recent National Assessment of Educational Progress (NAEP) report shows that only $36 \%$ of all 8 th graders in the U.S. are at or above the proficient level as of 2013 (The Nation's Report Card, 2013) while the same number is 31\% for Arizona. On the 2013 Arizona Instrument to Measure Standards. (AIMS) test, the percentage of students passing the mathematics portion was only $58 \%$ in grade 8 (Arizona Department of Education, 2014).

Two major documents guiding mathematics curriculum development, the Principles and Standards in School Mathematics (National Council of Teachers of Mathematics, 2000) and the Common Core Standards in Mathematics (National Governors Association Center for Best Practices, Council of Chief State School Officers, 2010) not only specify the big ideas in mathematics and the mathematical practices that must be mastered at the middle-school level, but also point out the centrality of these key concepts and habits of mind to the study of more advanced topics. Acknowledging students' poor performance in mathematics and recognizing the difficulties that they are having with learning mathematics, mathematics educators and researchers, nationwide, are searching for strategies to enhance interest and achievement in mathematics. Several researchers have studied and demonstrated the positive correlation between interest and achievement in mathematics (Fennema \& Romberg, 1999; Koller, Baumert, \& Schnabel, 2001; Simpkins, Davis-Kean, \& Eccles, 2006).

\section{Significance of Mathematics in General and Middle School Mathematics in Particular}

Mathematics is crucial to not only success in school studies, but also for being an informed citizen, being productive in one's chosen career, and being personally fulfilled. In today's technology driven society, greater demands have been placed on individuals to interpret and use mathematics to make sense of information and complex situations (Wedege, 2009-2010).

Several researchers have pointed out success with middle school mathematics is not only closely aligned to achievement with high school mathematics (Wang and Goldschmidt, 2003; Nathan and Koellner, 2007), but also for preparation for careers in science, engineering, and technology (Tai et al., 2006). Students from all income levels who take a rigorous K-12 mathematics sequence are more likely to go to college than those who do not (Rose and Betts, 
2001; Zelkowski, 2011). Later in the job market, students who have strong mathematics backgrounds are more likely to be employed and earn more than those with insufficient mathematical skills (Rose \& Betts, 2001; Joensen \& Nielsen, 2013), as noted by other researchers.

During the middle school years, mathematical concepts become increasingly complex and more abstract. Understanding of those concepts necessitates the ability to link across several algebraic and graphical representations (Rochelle et al., 2010).

In an effort to strengthen mathematics education in the U.S., the Common Core State Standards for Mathematics (NGA \& CCSSO, 2010) were created. The standards are designed to be robust and relevant to the real world, reflecting the body of knowledge and skills students should acquire in order to be prepared to study more advanced mathematics, become college and career ready, and ultimately get ready to compete successfully in the global economy. The Common Core State Standards for Mathematics aims to lay the foundations in grades 6 and 7 for the abstract topics of algebra and geometry to be covered in grade 8 (NGA \& CCSSO, 2010). Middle school mathematics, is therefore a cornerstone for STEM based career paths curricula not only during middle school but throughout high school, college and later in professional life as well.

\section{Data Driven Intervention Programs}

The urge to yield positive test results has motivated various schools and districts to drive change using the well-researched data. The focal point of data-driven reform is a move towards achieving appropriate, constructive information, understanding the "root causes" for low numbers, and implementing results aimed at bringing about improvement in backward areas. The main premise behind this is to utilize resources and hard work most proficiently in areas where it will make a considerable difference and to decompose the intimidating task of transforming entire schools and districts into smaller attainable tasks that can be achieved in a given time frame, thus motivating the front-line educators that they can easily withstand and overcome long-term problems.

Data-driven reform focuses on gathering, analyzing, and distributing data proposed to direct district and school reforms. Bernhardt (2003) listed four classes of data the districts should focus on: the learning curve of students, demographics, processes adopted by schools, and perception of teachers. These allow intellectual individuals in schools to spot the various problems encountered by students and teachers, to decompose the data to point out the individual schools and various demographic requiring special assistance, and identify problems that cause them to lag behind (Kennedy, 2003; Schmoker, 2003). Data-based decision making usually uses widespread expert development allowing school leaders to target long-term goals, utilize resources efficiently, and devise strategies for long-term growth (Conrad \& Eller, 2003).

Although data-driven reform strategies have yielded positive results, such strategies have not been popular and therefore have not been supported by as strong evidence as they deserve. The little evidence that does exist is based mainly of case studies on schools or districts that 
have already crossed the bar for state standards. For example, the Council of the Great City Schools (2002) named several urban districts that constantly defy the odds in achieving stellar student performance due to their endurance, skillful planning, and broad use of data for implementing decisions. Various case studies of out-performing districts and states have highlighted the same positive trends (Snipes, Doolittle, \& Herlihy, 2002; Streifer, 2002). However, such case studies reveal explanations only after the results have already been obtained. There is no evidence to suggest that the schools and districts that did not meet the standards may or may not be have using the same data-driven reform model (see Herman et al., 2008).

\section{Methodology}

A data driven and multifaceted intervention program was created and individualized for the needs of the most populated school where it was piloted in the district. The intervention started at the beginning of the school year and went on throughout the entire school year. It contained multiple facets and it was evaluated by Galileo Benchmark Tests and the Statewide High Stakes Test called the AIMS.

\subsection{The AIMS Test}

Conforming to the No Child Left Behind (NCLB) Act of 2001, the state of Arizona has been employing a standardized testing system entitled Arizona's Instrument to Measure Standards or AIMS (AIMS, 2014). The purpose of AIMS is to track how well students are doing in comparison with the state standards. All students attending grades 3 through 8 and 10 take the AIMS test in mathematics and English, both reading and writing. The AIMS test is based on the Arizona state standards, which define what students should be learning each year. AIMS results show the level of proficiency a student demonstrates in each of the subject areas tested. For each student taking the AIMS test on a particular content area, the raw score, the scaled score, the placement rating and a pass/fail index is reported. In this study, the instrument predominantly used is the scores on the statewide AIMS Tests. The raw score is the number of questions answered correctly from which the scaled score is calculated based on the mean and standard deviation of the scores of all test-takers. Placement rating can have 4 values; 1 (FFB - Falls Far Below), 2 (AS - Approaches the Standards), 3 (MS - Meets the Standards), and 4 (ES - Exceeds the Standards); 1 and 2 correspond to Fail whereas 3 and 4 correspond to Pass. Pass/fail index is either a $\mathrm{P}$ (Pass) or an F (Fail).

\subsection{The Galileo Benchmark Tests}

On a regular basis, districts adopting the data-driven reform model have to undergo proper qualified assessments three to five times in a year to decide if the students are on the road to improvement or not. The main focus is to identify small problems and to overcome them at their roots before they turn into bigger ones. Even though this sounds like a good strategy, these assessments have not been properly evaluated. Evidence suggest that assessments that are done more frequently impact performance more positively than those done yearly. (Schmoker, 1999), but this is different from evaluation done directly of a specific application as part of the benchmark assessment. 
The intervention to be reported in this paper took place at an elementary school district that adopted Galileo Benchmark assessment tests administered five times in a school-year. Galileo Benchmark test results are known to have strong positive correlations with the state-wide high stakes test called Arizona's Instruments to Measure Standards (AIMS) test results. Therefore, it was possible to forecast what various student groups would have achieve on the AIMS tests. Unique software allowed school leaders and teachers to observe the data according to the state standards, and its various categories of students, classes etc. These benchmark assessments gave district and school leaders accurate, proper information on improving student performance, proving them with the opportunity to undergo transformation in a limited time-scale. As a result, the district decided to pilot a data-driven multifaceted intervention program in the most populated school in the district. This program will be detailed in the next section.

\subsection{Individualized and Multifaceted Intervention Program}

The first facet was comprised of the data collected from the five Galileo Benchmark tests, namely the math pretest (MathPre) that took place in the beginning of the school year; the first, second and third benchmark math tests that took place at the end of the first, second and third quarters (Math1, Math2 and Math3 respectively) and finally the math posttest (MathPost) that took place at the end of the school year. Please note that the school year was divided to four quarters. First semester of the school year covered the first and second quarters and the second semester covered the third and fourth quarters.

The second facet comprised of a professional development program tailored for the needs of the twelve 8th grade teachers in the pilot school. The professional development program included test taking strategies, effective teaching, integrating test prep to everyday teaching, overcoming students' common misconceptions and harder to grasp 8th grade mathematics topics in addition to the review of all AIMS mathematics formulas and how they are utilized. The potentially problematic areas included multiplication tables up to 25; squares and square-roots; cubes and cube-roots; operations on signed numbers; the order of operations; common misconceptions such as associative property of multiplication vs. distributive property of multiplication over addition; decimals, fractions, percentages, and conversions of these to one another; and finally proportional reasoning. The teachers were expected to apply what they had learned in the professional development program in their mathematics classes and give an emphasis on the topics covered.

The third facet constituted the individualized instruction based on the data collected (hence the term data driven); it was put in place immediately after the pretest and it was revised after each benchmark test. Based on the test results each student potentially fell into one of three categories. Tier 1 comprised of students whose scores met (MS) or exceeded (ES) the standards. Tier 2 contained the students whose scores approached the standards (AS) and finally tier 3 students were the ones whose scores were falling far below the standards (FFB).

Tier 1 students needed no additional tutoring. They only concentrated on the concepts they missed during regular, day to day instruction. Tier 2 and tier 3 students both had to go through two weeks of a diagnostic testing program which identified their weaknesses 
followed by additional tutoring during the activity period when their weaknesses were addressed first. These students then reviewed the basic and more abundant topics in the AIMS mathematics test during tutoring while receiving the exact same instruction as tier 1 students in class.

Ultimately, the purpose of this intervention was to improve the AIMS mathematics scores of this school. In other words, the research question was, will the intervention create a statistically significant improvement on this year's AIMS mathematics scores (AIMSMathNew) in reference to last year's AIMS mathematics scores (AIMSMathOld).

\subsection{Participants}

The intervention targeted 277 eighth grade students that constituted the treatment group. The control group included the 8th grade students in the two other middle schools in the district. Of the students who were subjected to the intervention, 53\% were females and $47 \%$ were males. The district served free breakfast and lunch to $99 \%$ of all students as an indicator of their low SES. All schools in the district were classified as Title I. 94\% of the students were Hispanic, 2.6\% were Caucasian and 2\% were African-American.

\subsection{Classroom Walkthroughs}

In order to make sure that the intervention proceeded as planned, district leaders conducted classroom walkthroughs which provided valuable feedbacks into the value of education, effective classroom management, motivation of students, and proper organizations in the intervention school. District leaders analyzed and evaluated the execution professional development program, student participation and the educational standards of the intervention school occasionally discovering weaknesses in the program and resolving them as quickly as possible.

\section{Comparative Analyses and Results}

Table 1 shows the Benchmark test scores for the control and treatment groups throughout the school year. All comparative analyses were conducted at the significance level of 0.05 . The norms for $\eta_{\mathrm{p}}{ }^{2}$ (partial eta-squared) used are as follows: small $=0.01$; medium $=0.06$; large $=$ 0.14. The only factor was Group with two levels (Control and Treatment).

Table 1. Galileo Benchmark test scores for the control and treatment groups throughout the school year

\begin{tabular}{lccccccccccc}
\hline & \multirow{2}{*}{$\mathrm{N}$} & \multicolumn{2}{c}{ MathPre } & \multicolumn{2}{c}{ Math1 } & \multicolumn{2}{c}{ Math2 } & \multicolumn{2}{c}{ Math3 } & \multicolumn{2}{c}{ MathPost } \\
\cline { 3 - 12 } & & Mean & SD & Mean & SD & Mean & SD & Mean & SD & Mean & SD \\
\hline Control & 153 & 1292 & 83.9 & 1332 & 115.8 & 1283 & 109.8 & 1305 & 117.5 & 1311 & 105.3 \\
Treatment & 277 & 1291 & 79.8 & 1342 & 122.6 & 1302 & 93.0 & 1348 & 128.0 & 1391 & 120.6 \\
\hline
\end{tabular}

In order to assess where the control and treatment groups stood before any intervention took place in the beginning of the school year, an analysis of variance (ANOVA) was conducted 
where the dependent variable was MathPre. Results showed no statistically significant difference between the control and treatment groups before the intervention: $F(1,365)=$ $0.023, p>0.05$.

In order to assess the differences between the control and treatment groups toward the end of the first quarter about one quarter after the intervention, an analysis of variance with a covariate (ANCOVA) was conducted where the dependent variable was Mathl and the covariate was MathPre. Although the treatment group marginally did better than the control group, results were not statistically significant: $F(1,344)=1.796, p>0.05$.

In order to assess the differences between the control and treatment groups toward the end of the second quarter about two quarters after the intervention, an ANCOVA was conducted where the dependent variable was Math2 and the covariate was MathPre. The treatment group outperformed the control group and the results were statistically significant with small effect size: $F(1,356)=8.645, p<0.05, \eta_{\mathrm{p}}{ }^{2}=0.024$.

In order to assess the differences between the control and treatment groups toward the end of the third quarter about three quarters after the intervention, an ANCOVA was conducted where the dependent variable was Math3 and the covariate was MathPre. The treatment group outperformed the control group and the results were statistically significant with small to medium effect size: $F(1,359)=17.480, p<0.05, \eta_{\mathrm{p}}{ }^{2}=0.046$.

In order to assess the differences between the control and treatment groups toward the end of school year after a year of intervention, an ANCOVA was conducted where the dependent variable was MathPost and the covariate was MathPre. The treatment group outperformed the control group and the results were statistically significant with large effect size:

$F(1,358)=70.714, p<0.05, \eta_{\mathrm{p}}^{2}=0.165$.

Table 2 shows this year's and last year's AIMS Mathematics test scores for the control and treatment groups. In order to assess where the control and treatment groups stood last year in terms of AIMS mathematics test scores before any intervention took place, an ANOVA was conducted where the dependent variable was AIMSMathScaleOld. Results showed no statistically significant difference between the control and treatment groups before the intervention: $F(1,367)=0.045, p>0.05$.

Table 2. This year's and last year's AIMS Mathematics test scores for the control and treatment groups

\begin{tabular}{lccccc}
\hline & \multirow{2}{*}{$\mathrm{N}$} & \multicolumn{2}{c}{ AIMSMathScaleOld } & \multicolumn{2}{c}{ AIMSMathScaleNew } \\
\cline { 3 - 6 } & & Mean & SD & Mean & SD \\
\hline Control & 153 & 407 & 50.0 & 428 & 50.6 \\
Treatment & 277 & 408 & 51.2 & 442 & 52.6 \\
\hline
\end{tabular}

In order to assess the differences between the control and treatment groups in terms of this year's AIMS mathematics test scores an ANCOVA was conducted where the dependent 
variable was AIMSMathScaleNew and the covariate was AIMSMathScaleOld. The treatment group outperformed the control group and the results were statistically significant with small to medium effect size: $F(1,366)=17.991, p<0.05, \eta_{\mathrm{p}}{ }^{2}=0.047$.

\section{Discussion of Results}

The data driven, multifaceted and individualized intervention program piloted was a success. The first facet comprised of the data collected from the five Galileo Benchmark tests administered throughout the school year. The second facet consisted of a professional development program tailored for the needs of the twelve 8th grade teachers in the pilot school and included test taking strategies, effective teaching strategies, integrating test prep to everyday curricula, overcoming students' common misconceptions, review of the basics in middle school mathematics that typical 8th grade students would struggle with and finally review of the AIMS mathematics concepts and formulas. The third facet was the individualized instruction based on the data collected, put in place immediately after the pretest and revised after each benchmark test. The fourth and final facet was the classroom walkthroughs by the district leaders so as to enforce the implementation of the intervention program making tweaks and/or corrections as necessary.

The control and treatment groups essentially started at the same level based on the results of the math pretest. The first benchmark test showed some improvement in favor of the treatment group although the results were not statistically significant. The second and third benchmark tests as well as the posttest revealed statistically significant progress of the treatment group. At each of these tests, the treatment group outperformed the control group with the gap between average scores of the control and treatment groups as well as the effect size increasing at each subsequent test. The AIMS test which was administered shortly before the third benchmark test in April, confirmed the fact that the treatment group performed statistically significantly better than the control group; ultimately, the AIMS test was the targeted test and acing this test represented the primary objective of the intervention program.

\section{Conclusion}

It is important to note that intervention programs are not usually expected to produce effective results in the first year of implementation. The widespread opinion is that first year interventions are crucial in only taking the patient's temperature, not starting the treatment (Slavin et al., 2010). This was not the case in the intervention program depicted in this paper. The success of the intervention program was due to not only its careful planning but also the careful execution of its aspects that were all in place. The action-driven steps taken by the district leaders on the basis of the data collected impacted test results positively.

It must also be emphasized that the intervention took place at a high-poverty minority school. Yet, it was a success proving to be a cheap, scalable strategy that can be implemented to improve the performance of high-poverty schools. As a result, the intervention program became standard practice in the new school year.

The success of this intervention program suggests that districts or schools willing to consider reform in teaching should approach them directly. It is not a surprise that the district has 
initiated a similar intervention program in the beginning of the new school year at each of its schools since the intervention is already tried, tested and proven to create favorable results. However, there is never a one size fits all solution and the intervention program implemented in this study was not one, either. A major advantage of the program, however, was that it individualized in accordance with the needs of the school where it was implemented.

There is no evidence in the literature that points to the fact that the sole focus of school leaders on data is likely to produce anticipated outcomes. An intervention program can produce positive outcomes if and only if there are eager volunteers who believe in the program and implement all aspects of it to the letter.

\section{References}

Arizona Department of Education. (2009). Arizona's instrument for measuring standards: AIMS report wizard.

Arizona Department of Education. (2014). AIMS Assessment Results. Retrieved from http://www.azed.gov/research-evaluation/aims-assessment-results/

Bernhardt, V. L. (2003). No schools left behind. Educational Leadership, 60(5), 26-30.

Conrad III, W. H., \& Eller, B. (2003). District Data-Informed Decision Making.

Council of the Great City Schools. (2002). Beating the odds II. Washington, DC: Authors.

Couto, V. M. (2007). The globalization of white-collar work: The facts and fallout of next-generation offshoring. Retrieved January 26, 2013, from Duke University Fuqua School of Business Offshoring Research Network: https://offshoring.fuqua.duke.edu/pdfs/gowc_v4.pdf

Fennema, E., \& Romberg, T. A. (1999). Mathematics classrooms that promote understanding. New Jersey: Lawrence Erlbaum Associates, Publishers.

Herman, R., Dawson, P., Dee, T., Greene, J., Maynard, R., Redding, S., \& Darwin, M. (2008). Turning around chronically low-performing schools: A practice guide (NCEE \#2008-4020). Washington DC: Institute of Education Sciences, U.S. Department of Education. Retrieved from http://ies.ed.gov/ncee/wwc/practiceguides.

Institute of Education Sciences (IES). (2011). Mathematics Achievement of Fourth- and Eighth-Graders in 2011. Retrieved from http://nces.ed.gov/timss/results11_math11.asp

Ischinger, B. (2007). Education at a Glance 2007 OECD Indicators.

Joensen, J. S., \& Nielsen, H. S. (2013). Math and gender: is math a route to a high-powered career?. IZA.

Kelly, D., Nord, C. W., Jenkins, F., Chan, J. Y., \& Kastberg, D. (2013). Performance of US 15-Year-Old Students in Mathematics, Science, and Reading Literacy in an International Context. First Look at PISA 2012. NCES 2014-024. National Center for Education Statistics.

Kennedy, E. (2003). Raising test scores for all students: An administrator's guide to 
improving standardized test performance. Thousand Oaks, CA: Corwin Press.

Kier, M. W. (2013). Examining the effects of a STEM career video intervention on the interests and STEM professional identities of rural, minority middle school students (Doctoral dissertation, NORTH CAROLINA STATE UNIVERSITY).

Koller, O., Baumert, J., \& Schnabel, K. (2001). Does interest matter? The relationship between academic interest and achievement in mathematics. Journal for Research in Mathematics Education, 32, 448-470. http://dx.doi.org/10.2307/749801

Mullis, V. S., Martin, M. O., \& Foy, P. (2008). TIMSS 2007 international mathematics report: Findings from the IEA's trends in international mathematics and science study at the fourth and eighth grades. Boston, MA: TIMSS \& PIRLS International Study Center, Lynch School of Education, Boston College.

Nathan, M. J., \& Koellner, K. (2007). A framework for understanding and cultivating the transition from arithmetic to algebraic reasoning. Mathematical Thinking and Learning, 9(3), 179-192. http://dx.doi.org/10.1080/10986060701360852

National Council of Teachers of Mathematics (NCTM). (2000). Principles and Standards for School Mathematics. Retrieved January 1, 2013, from National Council of Teachers of Mathematics: http://www.nctm.org/standards/content.aspx?id=16909

National Governors Association (NGA) Center for Best Practices, Council of Chief State School Officers (CCSSO). (2010). The Standards. Retrieved January 1, 2013, from Common Core State Standards Initiative: http://www.corestandards.org/the-standards

National Research Council (NRC). (2007). Rising Above The Gathering Storm: Energizing and Employing America for a Brighter Economic Future Committee on Prospering in the Global Economy of the 21st Century: An Agenda for American Science and Technology. Washington, DC: National Academy of Sciences, National Academy of Engineering, Institute of Medicine, National Academy Press.

National Science Board. (2010). Science and engineering indicators 2010. Arlington, VA: National Science Foundation.

Riegle-Crumb, C., Moore, C., \& Ramos-Wada, A. (2011). Who wants to have a career in science or math? Exploring adolescents' future aspirations by gender and race/ethnicity. Science Education, 95(3), 458-476. http://dx.doi.org/10.1002/sce.20431

Roschelle, J., Shechtman, N., Tatar, D., Hegedus, S., Hopkins, B., Empson, S., ... Gallagher, L. P. (2010). Integration of Technology, Curriculum, and Professional Development for Advancing Middle School Mathematics Three Large-Scale Studies. American Educational Research Journal, 47(4), 833-878. http://dx.doi.org/10.3102/0002831210367426

Rose, H., \& Betts, J. R. (2001). Math matters: The links between high school curriculum, college graduation, and earnings. Public Policy Institute of California.

Schmoker, M. (1999). Results: The key to continuous school improvement (2nd ed.). 
Alexandria, VA: ASCD.

Schmoker, M. (2003). First things first: Demystifying data analysis. Educational Leadership, $60(5), 22-25$.

Simpkins, S. D., Davis-Kean, P. E., \& Eccles, J. S. (2006). Math and science motivation: A longitudinal examination of the links between choices and beliefs. Developmental Psychology, 42, 70-83. http://dx.doi.org/10.1037/0012-1649.42.1.70

Slavin, R. E., Holmes, G., Madden, N. A., Chamberlain, A., Cheung, A., \& Borman, G. D. (2010). Effects of a data-driven district-level reform model. Center for Research and Reform in Education.

Snipes, J., Doolittle, F., \& Herlihy, C. (2002). Foundations for success: Case studies of how urban school systems improve student achievement. Washington, DC: Council of the Great City Schools.

Tai, R. H., Qi Liu, C., Maltese, A. V., and Fan, X. (2006). Career choice enhanced: Planning early for careers in science. Science, 312, 1143-1144. http://dx.doi.org/10.1126/science.1128690

The Nation's Report Card. (2013). 2013 Mathematics and Reading. Retrieved from http://nationsreportcard.gov/reading_math_2013/\#/

U.S. Congress Joint Economic Committee. (2012). STEM Education: Preparing for the Jobs of the Future. Washington DC.

U.S. Department of Labor, Employment and Training Administration by Jobs for the Future. (2007). The STEM Workforce Challenge: the Role of the Public Workforce System in a National Solution for a Competitive Science, Technology, Engineering, and Mathematics (STEM) Workforce. Washington D.C.

Wang, J., \& Goldschmidt, P. (2003). Importance of middle school mathematics on high school students' mathematics achievement. The Journal of Educational Research, 97(1), 3-19. http://dx.doi.org/10.1080/00220670309596624

Wedege, Tine. (2009). Needs versus demands: Some ideas on what it means to know mathematics in society.

Wedege, Tine. (2010). People's mathematics in working life: Why is it invisible? Adults Learning Mathematics - an International Journal, 5(1), 89-97.

\section{Copyright Disclaimer}

Copyright reserved by the authors.

This article is an open-access article distributed under the terms and conditions of the Creative Commons Attribution license (http://creativecommons.org/licenses/by/3.0/). 